\begin{abstract}
Introduction: Helicobacter pylori (H. pylori) is a non-invasive microorganism causing intense gastric mucosal inflammatory and immune reaction. $H$. pylori-induced gastric mucosal cytokine overproduction has been clearly documented previously. The stomach has a large surface area and continuous spill-over of locally produced cytokines into the blood stream is a possibility. There are few and conflicting data on circulatory proinflammatory cytokine levels in patients with $H$. pylori infection. Materials and methods: Forty-two dyspeptic patients were enrolled into the study. The presence of $H$. pylori infection was diagnosed with antral histopathologic examination. After overnight fasting; serum samples were obtained from each patient to determine circulating interleukin (IL)-6, IL-8 and tumor necrosis factor- $\alpha$ (TNF- $\alpha$ ) levels.

Results: H. pylori was shown in 30 cases using Giemsa stain in antral histopathologic evaluation. Twelve cases were negative for $H$. pylori staining. Both the age and sex distribution had an insignificant difference in both $H$ pylori-positive and $H$. pylorinegative groups. The mean circulatory levels of IL-6, IL-8 and TNF-a in both groups were not different. The situation was same in respect to the serum levels of these cytokines and the degree of inflammation, $H$. pylori density and activation scores according to Sydney classification.

Conclusion: We could not show elevated circulatory levels of IL-6, IL-8 and TNF- $\alpha$ in $H$. pylori-infected cases. We believe that $H$. pylori-related cytokine activation become concentrated on gastric mucosa and this pathogen-induced local inflammatory cascade does not cause changes in circulatory levels of these cytokines. Moreover, there is no correlation between the levels of serum cytokines and Sydney parameters.
\end{abstract}

Key words: Helicobacter pylori infection, Interleukin-6, Interleukin-8, Tumor necrosis factor- $\alpha$, Sydney parameters

\section{Serum levels of tumor necrosis factor- $\alpha$, interleukin- 6 and interleukin-8 are not increased in dyspeptic patients with Helicobacter pylori-associated gastritis}

Taner Bayraktaroğlu',CA, Ahmet Şükrü Aras², Selim Aydemir ${ }^{3}$, Can Davutoğlu ${ }^{4}$, Yücel Üstündağ ${ }^{3}$, Hulusi Atmaca ${ }^{1}$ and Ali Borazan ${ }^{1}$

\section{${ }^{1}$ Department of Internal Medicine, and}

${ }^{3}$ Gastroenterology Department, Faculty of Medicine, Zonguldak Karaelmas University, 67600 Zonguldak, Turkey; ${ }^{2}$ Department of Endocrinology Metabolism and Nutrition, Faculty of Medicine, Istanbul University, Turkey; ${ }^{4}$ Gastroenterology Department, İstanbul Vakif Gureba, Education Hospital, Istanbul, Turkey

\author{
${ }^{\mathrm{CA}}$ Corresponding author \\ Fax: +90 3722610155 \\ E-mail: baytaner@yahoo.com
}

\section{Introduction}

In many gastrointestinal infections, the inflammatory response induced by the pathogen can be an important contributor to mucosal damage and epithelial dysfunction. Possibly the best example of this is the infection with Heliobacter pylori microorganisms. H. pylori leads to mucosal increases in many proinflammatory and immunoregulatory cytokines, and also increases in members of the chemokine group of peptides. ${ }^{1}$ As a most probable target in $H$. pylori infection, and a major interface between the host and pathogen, the epithelial cell initiates acute mucosal inflammation and interacts with the other mucosal cell populations via a cytokine network. ${ }^{2}$ These two responses may be regulated differentially following induction of cytokines involved in the inflammatory cascade, including tumor necrosis factor- $\alpha$ (TNF- $\alpha$ ), interleukin (IL)-1, IL-6, and IL-8. ${ }^{3-6}$

The stomach has a large surface area. A suggestion that the chronic gastric mucosal inflammation induced by $H$. pylori potentially may have systemic effects based on increases in serum proinflammatory cytokines seems not to be bizarre. Although cytokine-based gastric mucosal immune response to $H$. pylori infection has been documented very well, very minute data on circulating levels of particular proinflammatory cytokines are available. Moreover, the present few data are contradictory. ${ }^{7-10}$ In our study, we investigated circulating levels of IL-8, IL-6 and TNF- $\alpha$ in patients with $H$. pylori infection. 


\section{Research design and methods}

\section{Patients}

Forty-two patients with dyspeptic symptoms enrolled into the study. Patients who received anti-bacterial treatment for H. pylori and anti-ulcer drugs 1 month prior to the study or who had undergone vagotomy or stomach resection were excluded.

\section{Assessment of the state of $H$. pylori infection}

The state of $H$. pylori infection was assessed histologically. The biopsy specimens were fixed in 10\% formalin and embedded in paraffin. H. pylori was determined by Giemsa staining. The density of H. pylori was graded as 'none', 'mild', 'moderate', and 'severe' according to the Sydney system, ${ }^{11}$ and scored on a $0-3$ scale. When at least one of the two biopsies of each patient yielded a positive result, the patient was considered as positive for H. pylori.

\section{Histological assessment of gastritis}

Sections were also stained with hematoxylin and eosin. The severity of chronic and acute inflammation, atrophy, and intestinal metaplasia was graded as 'none', 'mild', 'moderate', and 'severe' according to the Sydney system and scored on a $0-3$ scale. ${ }^{11}$

\section{IL-8, IL- 6 and TNF- $\alpha$ assays}

Blood samples were taken after overnight fast and after $30 \mathrm{~min}$ in the supine position to determine serum IL-8, IL-6 and TNF- $\alpha$. Samples were stored at $-20^{\circ} \mathrm{C}$. Serum cytokine concentrations were determined in triplicate using a commercial enzyme-linked immunosorbent assay (Immulite IL-8, Immulite IL-6, Immulite TNF- $\alpha$; DPC, Los Angeles, CA, USA). The sensitivities of these assays are approximately $2 \mathrm{pg} /$ $\mathrm{ml}, 1 \mathrm{pg} / \mathrm{ml}$ and $1.7 \mathrm{pg} / \mathrm{ml}$ for IL-8, IL-6 and TNF- $\alpha$, respectively.

\section{Statistical analysis}

Results are expressed as the mean \pm standard deviation. In the comparison between groups, statistically significant differences were assessed by the chisquare test and the Mann-Whitney U-test. $p<0.05$ was considered statistically significant.

\section{Results}

Our study group had a mean age of $44.5 \pm 11.9$ years (20-65 years). The male to female ratio was 20/22. The presence of $H$. pylori was seen in 32 patients. Twelve cases were negative for the presence of
H. pylori. Both the age and sex distribution had an insignificant difference in both groups. The Sydney classification scores in our cases are presented in Table 1. None of our cases had severe inflammation and atrophy. The situation was not different in respect to serum levels of these cytokines and the degree of inflammation, $H$. pylori density and activation scores according to the Sydney system $(p>0.05)$ (Table 2).

We could not detect statistically significant differences in the serum levels of these cytokines with respect to the presence or absence of $H$. pylori $(p>0.05)$.

\section{Discussion}

In the present study, we scrutinized the levels of circulatory cytokines, which may theoretically increase as a consequence of intense gastric mucosal cytokine activation. We know that infection with H. pylori leads to increases in many mucosal proinflammatory and immunregulatory cytokines such as IL-6, IL-8, IL-1 $\beta$, TNF- $\alpha$, interferon- $\gamma$, and plateletactivating factor. ${ }^{1}$ However, the primary modulator cytokine in H. pylori-associated gastritis is IL-8. ${ }^{12}$ H. pylori pathogenicity island encoding for Cag A protein and other virulence factors increases expression of IL-8, which in turn triggers the neutrophilic infiltration and induces cytokine release adherence to the epithelium. ${ }^{13}$ If we consider the total gastric surface area, which is nearly $700 \mathrm{~cm}^{2}$, it is not unwise to think that $H$. pylori-associated gastric local mucosal response may have systemic effects. ${ }^{14}$ As an example; one of these effects may be through hypergastrinemia. TNF- $\alpha$ increases serum gastrin levels by decreasing the somatostatin content in D cells in animal models. ${ }^{15}$ IL 8 increases the basal gastrin release from canine $G$ cells. ${ }^{16,17}$ As is generally known, gastrin has many extra-gastric effects, especially on intestinal and colonic epithelial growth and enteric immune response. ${ }^{18,19}$

In the present study we aimed to investigate whether we can show increased serum proinflammatory cytokines such as TNF- $\alpha$, IL- 8 and IL-6 in $H$. pylori-infected patients without systemic diseases. We could not demonstrate any increase in circulatory cytokines in H. pylori-positive patients. Although

Table 1. Sydney scores of our patients

\begin{tabular}{lllll}
\hline & Score 0 & Score 1 & Score 2 & Score 3 \\
\hline H. pylori & $12(28.6)$ & $25(59.5)$ & $5(11.9)$ & - \\
Inflammation & - & $15(35.7)$ & $27(64.3)$ & - \\
Activation & $22(52.4)$ & $20(47.6)$ & - & - \\
Atrophy & - & - & - & - \\
Metaplasia & $40(95.2)$ & $2(4.8)$ & - & - \\
\hline
\end{tabular}

Data presented as $n(\%)$. 
mucosal cytokine production was found to correlate well with the intensity of gastric mucosal inflammation, serum cytokine levels did not show correlation with Sydney parameters, including the gastric epithelial inflammatory scores, $H$. pylori density and activation, in the present study. ${ }^{3}$ In the literature, some authors reported increased circulatory TNF- $\alpha$ levels while serum IL-8 levels remained normal in H. pylori-infected persons. ${ }^{7}$ Some others reported elevated serum TNF- $\alpha$ levels in patients with CagApositive $H$. pylori infection. ${ }^{8}$ IL-1, IL- 6 and IL- 8 were all also elevated in Cag A-positive cases. ${ }^{20,21}$ We did not determine the Cag A status of our patients. Thus, we do not know whether most or all of our patients were infected with a Cag A-negative strain. However, we know that our patients neither had endoscopic sign of gastroduodenal ulceration nor had severe gastritis on histopathology. Therefore we possibly had patients infected with less pathogenic strains of this bacterium such as with Cag A-negative H. pylori . The other possibility may be the inhibition of further inflammation by a gastric protective cytokine IL-10. ${ }^{22}$ Although we do not measure its levels on gastric mucosal extracts and circulation, we know that IL-10 secreted by gastric mucosa has inhibitory effects on gastric mucosal immune response associated with local proinflammatory cytokine activation.

As a result of contradictory reports, including ours, we do not know whether the continuous spill-over of cytokines into the blood stream could be possible as a consequence of gastric mucosal cytokine activation and increased synthesis. If true, this may be a potential threat in patients with $H$. pylori infection for some 'extra-gastric' pathologies, such as coronary heart disease, primary Raynaud phenomenon, sideropenic refractory anemia and delayed growth in children. ${ }^{23-28}$ We think that further studies are needed to make firm conclusions on $H$. pyloriinduced changes in the circulatory cytokine levels.

\section{References}

1. Crabtree JE. Role of cytokines in pathogenesis of Helicobacter pyloriinduced mucosal damage. Dig Dis Sci 1998; 43: 46S-55S.

2. Stadnyk AW. Intestinal epithelial cells as a source of inflammatory cytokines and chemokines. Can J Gastroenterol 2002; 16: 241-246.

3. Ando T, Kusugami K, Ohsuga M, et al. Interleukin- 8 activity correlates with histological severity in Helicobacter pylori-associated antral gastritis. Am J Gastroenterol 1996; 91: 1150-1156.

4. Crabtree JE, Peichl P, Wyatt JI, Stachl U, Lindley IJD. Gastric interleukin-8 and IgA IL-8 autoantibodies in Helicobacter pylori infection. Scand J Immunol 1993; 37: 65-70.

5. Gionchetti P, Vaira D, Campieri M, et al. Enhanced mucosal interleukin6 and -8 in Helicobacter pylori-positive dyspeptic patients. Am J Gastroenterol 1994; 89: 883-887.

6. Noach LA, Bosma NB, Jansen J, Hoek FJ, van Deventer SJ, Tytgat GN. Mucosal tumor necrosis factor- $\alpha$, interleukin- $1 \beta$, and interleukin- 8 production in patients with Helicobacter pylori infection. Scand $J$ Gastroenterol 1994; 29: 425-429.

7. Russo F, Jirillo E, Clemente C, et al. Circulating cytokines and gastrin levels in asymptomatic subjects infected by Helicobacter pylori. Immunopharmacol Immunotoxicol 2001; 23: 13-24.

8. Perri F, Clemente R, Festa V, et al. Serum tumour necrosis factor-alpha is increased in patients with Helicobacter pylori infection and CagA antibodies. Ital J Gastroenterol Hepatol 1999; 31: 290-294. 
9. Cichoz-Lach H, Slomka M, Celinski K, Baczek A. Level of serum cytokines in biliary gastritis and erosive gastritis with Helicobacter pylori coinfection. Ann Univ Mariae Curie Sklodowska [Med] 2001; 56: $271-$ 274.

10. Bartuzi Z, Zbikowska-Gotz M, Romanski B, Sinkiewicz W. Evaluating the profile of selected cytokines in patients with food allergy and chronic gastritis. Med Sci Monit 2000; 6: 1128-1135.

11. Price AB. The Sydney system: histological division. $J$ Gastroenterol Hepatol 1991; 6: 209-222

12. Crabtree JE, Wyatt JI, Trejdosiewicz LK, et al. Interleukin-8 expression in Helicobacter pylori infected, normal, and neoplastic gastroduodenal mucosa. J Clin Pathol 1994; 47: 61-66.

13. Crabtree JE. Gastric mucosal inflammatory responses to Helicobacter pylori. Aliment Pharmacol Ther 1996; 10: 29-37.

14. Figura N. Progress in defining the inflammatory cascade. Eur $J$ Gastroenterol Hepatol 1995; 7: 296-302.

15. Beales I, Calam J, Post L, Srinivasan S, Yamada T, DelValle J. Effect of transforming growth factor alpha and interleukin 8 on somatostatin release from canine fundic D cells. Gastroenterology 1997; 112: 136 143.

16. Weigert N, Schaffer K, Schusdziarra V, Classen M, Schepp W. Gastrin secretion from primary cultures of rabbit antral $G$ cells: stimulation by inflammatory cytokines. Gastroenterology 1996; 110: 147-154.

17. Beales IL, Post L, Calam J, Yamada T, Delvalle J. Tumour necrosis factor alpha stimulates gastrin release from canine and human antral G cells possible mechanism of the Helicobacter pylori-gastrin link. Eur J Clin Invest 1996; 26: 609-611.

18. Genton L, Kudsk KA. Interactions between the enteric nervous system and the immune system: role of neuropeptides. Am J Surg 2003; 186 $253-258$

19. Koh TJ, Chen D. Gastrin as a growth factor in the gastrointestinal tract Regulat Pept 2000; 93: 37-44.
20. Noach LA, Bosma NB, Jansen J, Hoek FJ, van Deventer SJ, Tytgat GN. Mucosal tumor necrosis factor-alpha, interleukin-1 beta, and interleukin8 production in patients with Helicobacter pylori infection. Scand J Gastroenterol 1994; 29: 425-429.

21. Crabtree JE, Shallcross TM, Heatley RV, Wyatt JI. Mucosal tumour necrosis factor alpha and interleukin-6 in patients with Helicobacter pylori associated gastritis. Gut 1991; 32: 1473-1477.

22. Bodger K, Wyatt JI, Heatley RV. Gastric mucosal secretion of interleukin10: relations to histopathology, Helicobacter pylori status, and tumour necrosis factor-alpha secretion. Gut 1997; 40: 739-744.

23. Gasbarrini A, Franceschi F, Armuzzi A, et al. Extradigestive manifestations of Helicobacter pylori gastric infection. Gut 1999; 45: 9-12.

24. Mendall MA, Goggin PM, Molineaux N, et al. Relation of Helicobacter pylori infection and coronary heart disease. Br Heart J 1994; 71: $437-$ 439.

25. Gasbarrini A, Serricchio M, Tondi P, Gasbarrini G, Pola P. Association of Helicobacter pylori infection with primary Raynaud phenomenon. Lancet 1996; 348: 966-967.

26. Dufour C, Brisigotti M, Fabretti G, Luxardo P, Mori PG, Barabino A. Helicobacter pylori gastric infection and sideropenic refractory anemia. $J$ Pediatr Gastroenterol Nutr 1993; 17: 225-227.

27. Patel P, Mendall MA, Khulusi S, Northfield TC, Strachan DP. Helicobacter pylori infection in childhood: risk factors and effect on growth. Br MedJ 1994; 309: 1119-1123.

28. Perri F, Pastore M, Leandro G, et al. Helicobacter pylori infection and growth delay in older children. Arch Dis Child 1997; 77: 46-49.

Received 10 November 2003

Accepted 8 December 2003 


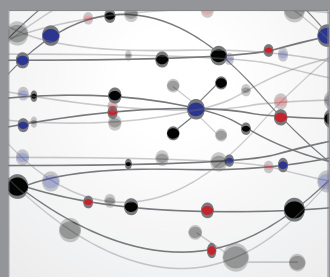

The Scientific World Journal
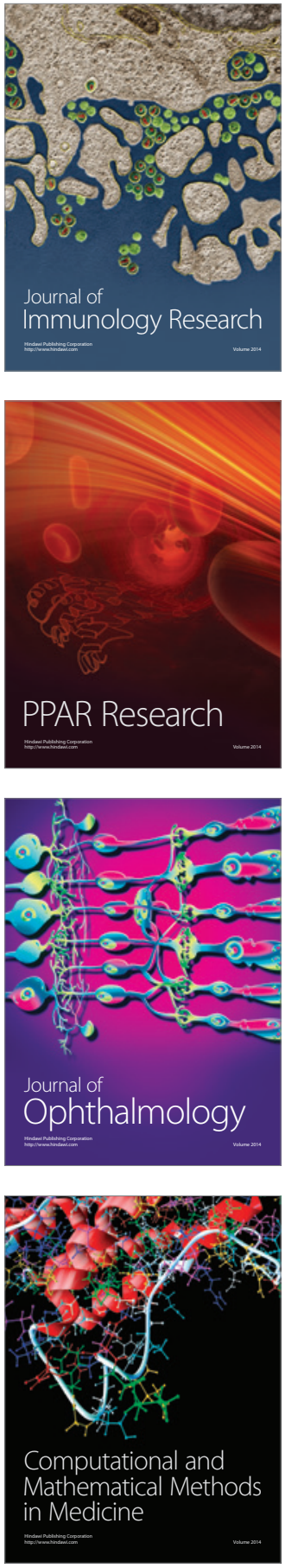

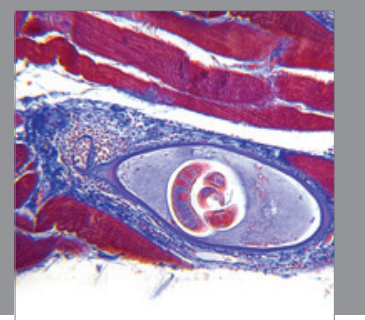

Gastroenterology

Research and Practice
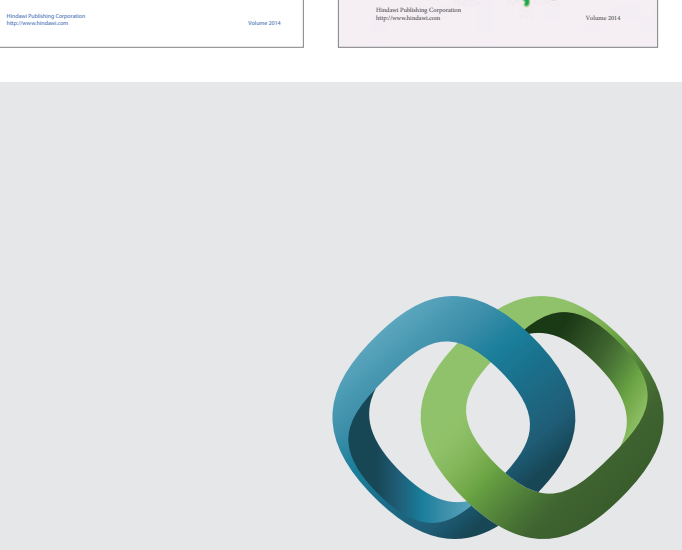

\section{Hindawi}

Submit your manuscripts at

http://www.hindawi.com
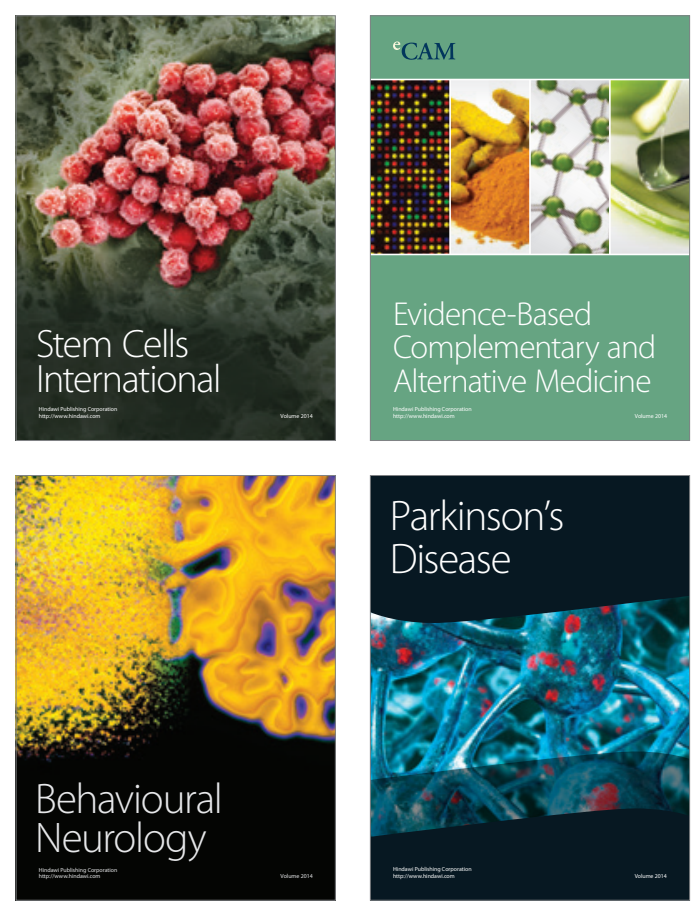

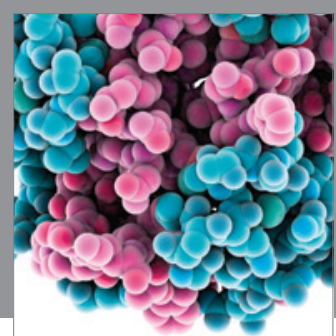

Journal of
Diabetes Research

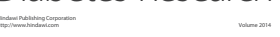

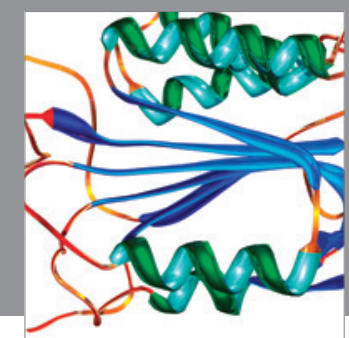

Disease Markers
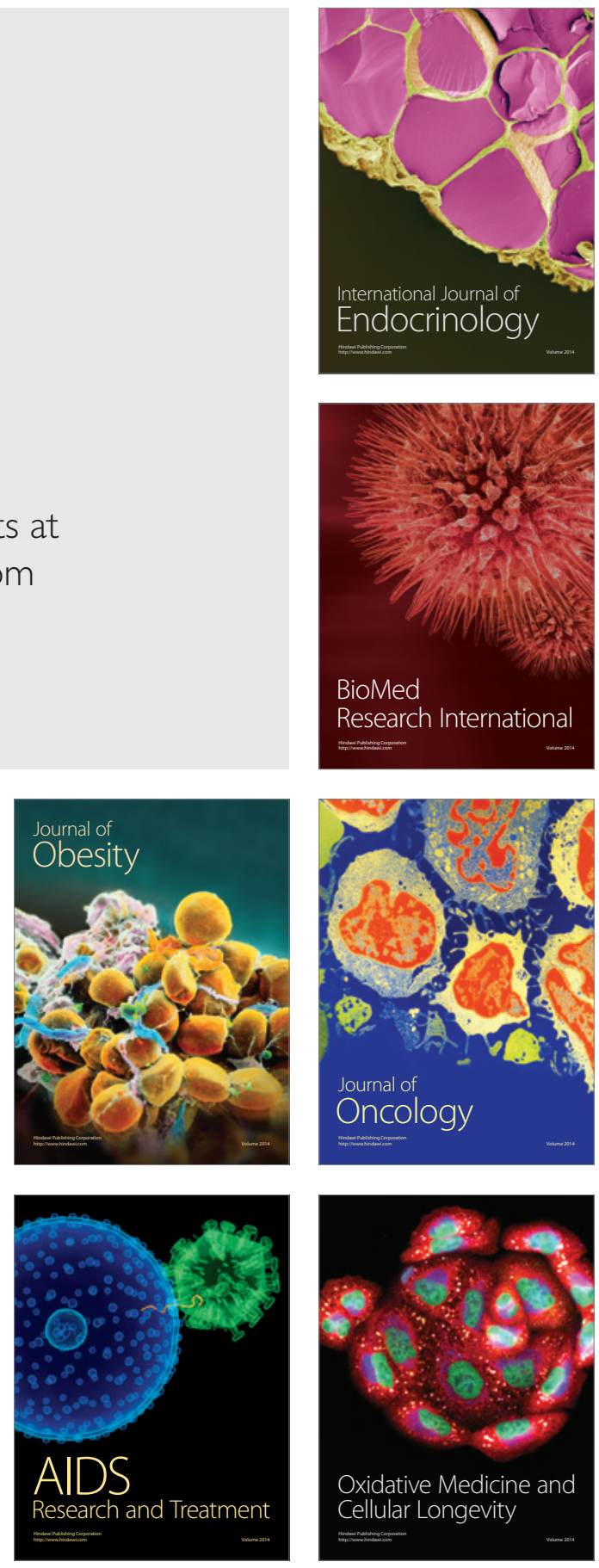